\title{
Prospective Study of the Changes in Pharmacotherapy Cost of Adult Kidney Transplant Patients in Bulgaria
}

\author{
Svetla Georgieva ${ }^{1}$, Guenka Petrova ${ }^{2,3 \#}$, Maria Dimitrova ${ }^{2}$, Lily Peikova $^{3}$, Emil Paskalev $^{4}$, \\ Jean Filipov ${ }^{4}$, Borelli Zlatkov ${ }^{4}$ \\ ${ }^{1}$ Hospital Pharmacy, University Hospital “Alexandrovska”, Medical University of Sofia, Sofia, Bulgaria \\ ${ }^{2}$ Department of Organisation and Economy of Pharmacy, Faculty of Pharmacy, Medical University of Sofia, Sofia, Bulgaria \\ ${ }^{3}$ Department of Pharmaceutical Chemistry, Faculty of Pharmacy, Medical University of Sofia, Sofia, Bulgaria \\ ${ }^{4}$ Nephrology and Transplantation Clinic, University Hospital “Alexandrovska”, Medical University of Sofia, Sofia, Bulgaria \\ Email: " guenka.petrova@gmail.com
}

Received October 8, 2013; revised November 8, 2013; accepted November 15, 2013

Copyright (C) 2013 Svetla Georgieva et al. This is an open access article distributed under the Creative Commons Attribution License, which permits unrestricted use, distribution, and reproduction in any medium, provided the original work is properly cited. In accordance of the Creative Commons Attribution License all Copyrights (C) 2013 are reserved for SCIRP and the owner of the intellectual property Svetla Georgieva et al. All Copyright (C) 2013 are guarded by law and by SCIRP as a guardian.

\begin{abstract}
The purpose of the study is to analyze the changes in the ambulatory pharmacotherapy cost of kidney transplant patients in Bulgaria during the years 2006-2011 and the factors influencing it. It is a prospective cost study of changes in ambulatory pharmacotherapy cost. The cost of pharmacotherapy was calculated per patient per year and per month on average. In total, 21 therapeutic schemes were prescribed for 589 individuals per year on average. Most often, the prescribed therapeutic scheme was ciclosporin + mycophenolate, 38\% to 39\% of all cases during 2006 and 2011 respectively. Average cost of therapy differs in great interval and depends on age of the patients, place of transplantation, life with the graft, development of the citomegalovirus infection etc. Our study shows that the average monthly cost of pharmacotherapy decreases during 2006-2011, as a result of introduction of generic immune suppressors. All evaluated factors influence the statistically significant cost of pharmacotherapy.
\end{abstract}

Keywords: Kidney Transplantation; Pharmacotherapy; Cost Analysis

\section{Introduction}

Renal transplantation is considered as successful therapy for chronic kidney disease [1]. After the transplantation, a life time pharmacotherapy with immunosuppressors [2] is necessary. Contemporary immunosuppressive therapy includes calcineurin inhibitors (CI), or cyclosporin, or tacrolimus, combined with at least one more medicine $[3,4]$. There are published evidences that the introduction of new immune suppressors increases the cost of pharmacotherapy, but maintains the graft longevity, improves quality of life and increases survival [3,5].

The cost of renal transplantation is widely studied from a national perspective [6-9]. There are a limited number of studies on the cost of immunosuppressive pharmacotherapy at a national level and the factors affecting it. This stimulates our interest towards this topic [10,11].

*Conflict of interests: The authors declare that there is no conflict of interests regarding the publication of this article.

\#Corresponding author.
The purpose of the study is to analyze the changes in the ambulatory pharmacotherapy cost of kidney transplant patients in Bulgaria during the years 2006-2011 and the factors influencing it.

We have explored several study questions:

1) What is the average monthly and yearly pharmacotherapy cost for kidney transplant patients?

2) Are there statistically significant differences in pharmacotherapy cost during the years and among different patients groups?

3) Which factors influence the pharmacotherapy cost?

\section{Methods}

It is a prospective cost study of changes in ambulatory pharmacotherapy cost for all adult patients in Bulgaria during the period 2006-2011. On total 598 adult patients were included in the study.

Prescribing practice analysis was performed as follows: from the patients' records and prescriptions, information 
about the prescribed medicines was collected on a monthly basis, changes in pharmacotherapy, new medicines introduction, addition of therapy for citomegalo virus infections and other patients' characteristics.

The cost of pharmacotherapy was calculated per patient per year and per month on average.

All costs are presented in national currency Bulgarian leva (BGN) at the ex-change rate of 1 Euro $=1.95$ BGN. Descriptive statistic, t-tests analyses were performed to evaluate the changes in the prescribing practice and cost of pharmacotherapy.

The regression analytical model "Curve estimation" was also used to test the relation between the cost of pharmacotherapy and patients' transplantation age, as well as between the pharmacotherapy cost and number of years after transplantation.

The analysis was done with the IBM SPSS Statistics 19.0.

\section{Results}

385 (64.4\%) male and 213 (35.6\%) female patients were observed, average age $44.08 \pm 12.51$ years. Prevailing part of the observed patients (64.4\%) were between 30 55 years of age, $20.7 \%$ were above $55 \%$, and $14.9 \%$ were 18 - 30 years old.

Kidney transplant patients are usually treated with different immune suppressors as mono therapy or in combination. On total 21 therapeutic schemes were found prescribed (Table 1). The number of patients on therapy during the years differs and it is also lower than all observed 589 individuals because some patients dropping out due to graft rejection. Most often, the prescribed therapeutic scheme was ciclosporin + mycophenolate; $38 \%$ to 39\% of all cases during 2006 and 2011 respectively. Sodium and mofetil salts of mycophenolate are considered as the same product. Second most often prescribed was the combination of cyclosporine + azathioprine in $48 \%$ to $18 \%$ of all cases with decreasing frequency. After the introduction of tacrolimus in 2008 its inclusion into the therapeutic schemes started to increase especially in combination with mycophenolate. Until 2011 only $19 \%$ of patients were prescribed that particular combination. All patients using micophenolate were aditionally prescribed corticosteroids, while for the other patients-only in case of necessity. The risk of graft rejection was managed with thymoglobulin, HBV infection was treated with lamivudine, and cytomegalovirus infection-with gancyclovir.

Average monthly cost of pharmacotherapy was varying among patients and years. An initial increase in the average monthly cost was observed from 2007 to 2009 after which the cost started to decrease. Almost all the changes in the average monthly cost were found to be statistically significant $(\mathrm{p}<0.05)$ - Table 2 . The descrip-
Table 1. Therapeutic schemes prescribed to kidney transplant patients in Bulgaria.

\begin{tabular}{|c|c|c|c|c|c|c|}
\hline \multirow{2}{*}{ Therapeutic shema } & \multicolumn{6}{|c|}{ Number of patients on therapy per year } \\
\hline & 2006 & 20007 & 2008 & 2009 & 2010 & 2011 \\
\hline Ciclosporin + mycophenolat & 157 & 169 & 200 & 170 & 191 & 170 \\
\hline Tacrolimus + mycophenolat & & & 2 & 49 & 89 & 84 \\
\hline Sirolimus + mycophenolat & 11 & 10 & 27 & 34 & 28 & 22 \\
\hline Everolimus + mycophenolat & & & 5 & 8 & 6 & 3 \\
\hline Ciclosporin + azathioprine & 195 & 204 & 157 & 101 & 88 & 79 \\
\hline Tacrolimus + azathioprine & & & & 23 & 2 & 18 \\
\hline Sirolimus + azathioprine & 2 & 2 & 4 & 2 & 20 & 2 \\
\hline Ciclosporin & 23 & 28 & 17 & 18 & 13 & 24 \\
\hline Sirolimus & 5 & 6 & 11 & 10 & 9 & 9 \\
\hline Mycophenolat & 8 & 7 & 10 & 9 & 10 & 7 \\
\hline Azathioprine & 9 & 8 & 5 & 2 & 2 & 2 \\
\hline Tacrolimus & & & 2 & 3 & 2 & 1 \\
\hline Everolimus & & & 1 & 1 & 1 & 1 \\
\hline Ciclosporin + sirolimus & & & 2 & 2 & 2 & 2 \\
\hline Ciclosporin + everolimus & & & 1 & & & \\
\hline Ciclosporin + sirolimus & & & 3 & 2 & 2 & 2 \\
\hline Everolimus + azathioprine & & & & 4 & 4 & 4 \\
\hline Ciclosporin + everolimus & & & & 1 & 1 & 1 \\
\hline $\begin{array}{l}\text { Ciclosporin + sirolimus + } \\
\text { azathioprine }\end{array}$ & & & & & 1 & \\
\hline Sirolimus + tacrolimus & & & & & 1 & 1 \\
\hline $\begin{array}{c}\text { Ciclosporin + everolimus + } \\
\text { azathioprine }\end{array}$ & & & & & & 1 \\
\hline Total number of patients & 410 & 434 & 447 & 439 & 472 & 433 \\
\hline
\end{tabular}

tive statistics shows that there is no constant average monthly cost of pharmacotherapy. It varies in a great range from 0 to $2800 \mathrm{BGN}$.

Detailed analysis of the changes in the prescribing and pharmacotherapy cost revealed that $n=291$ were on therapy during the whole observed period of 6 yearsTable 3. Out of all 598 observed from 412 to 473 were on therapy yearly, which means that around $20 \%$ dropped out. No statistically significant difference was found regarding the cost of pharmacotherapy and patients gender.

The question for patients' age at the moment of transplantation is important because older patients could have more damaged organs thus making the transplantation riskier. It could also affect the pharmacotherapy cost. By using the regression analysis was explored the relation among the cost of pharmacotherapy and patients' trans- 
Table 2. Average monthly cost of pharmacotherapy during 2006-2011 in BGN and standard deviation (SD).

\begin{tabular}{|c|c|c|c|c|c|c|c|c|c|c|c|}
\hline \multicolumn{2}{|c|}{2006} & \multicolumn{2}{|c|}{2007} & \multicolumn{2}{|c|}{2008} & \multicolumn{2}{|c|}{2009} & \multicolumn{2}{|c|}{2010} & \multicolumn{2}{|c|}{2011} \\
\hline & SD & & SD & & SD & & SD & & SD & & SD \\
\hline $336.14^{\mathrm{a}}$ & 336.24 & $346.26^{\mathrm{b}}$ & 332.16 & $341.94^{\mathrm{a}}$ & 323.53 & $412.95^{\mathrm{b}}$ & 385.92 & $323.31^{\mathrm{c}}$ & 338.67 & $270.74^{d}$ & 369.16 \\
\hline
\end{tabular}

*Same letters mean lack of statistically significant difference and different letters mean statistically significant differences in cost (p < 0.05).

Table 3. Distribution of patients on therapy.

\begin{tabular}{ccc}
\hline Number of years on therapy during 2006-2011 & $\mathrm{N}$ & $\%$ \\
\hline 6 & 291 & 48.66 \\
2 & 81 & 13.55 \\
5 & 68 & 11.37 \\
1 & 66 & 11.04 \\
3 & 49 & 8.19 \\
4 & 43 & 7.19 \\
\hline
\end{tabular}

plantation age (Figure 1). The relation is linear and is described with the following model parameters ( $\mathrm{p}=$ $\left.0.013, \mathrm{R}^{2}=0.013\right)$.

Expenses $=467815-2089 \times$ age of transplantation where:

Expenses - the average monthly pharmacotherapy cost during 6 years;

age of transplantation-patient age at the moment of transplantation.

Negative relation means that with the increase of patients' age when the transplantation is done the pharmacotherapy cost decreases. The calculated with the model decrease is with 2.1 monetary units.

Another explored relation is that among the pharmacotherapy cost and number of years after transplantation. This relation could be described with a cubic model ( $\mathrm{p}<$ $0.001, R^{2}=0.140$ ) with the following parameters:

$$
\begin{aligned}
\text { Expenses }= & 135.104+115.654 \times \text { Years AT } \\
& -11.516 \times \text { Years } A^{2}+0.309 \times \text { Years } A^{3} T^{3}
\end{aligned}
$$

where:

Expenses are the average monthly pharmacotherapy cost during 6 years;

Years AT-years after transplantation.

Graphically, the model is shown on Figure 2. During the first 8 years after the transplantation the cost increases, then following a 10 year decrease period begins to increase again.

The development of the citomegalovirus infection is a common complication which increases the probability of graft rejection. Table 4 shows the average 6 years pharmacotherapy cost for patients with and without citomegalovirus infections. Patients with infections possess
Table 4. Average monthly cost of 6 years therapy for patient with and without $\mathrm{CMV}$-infection.

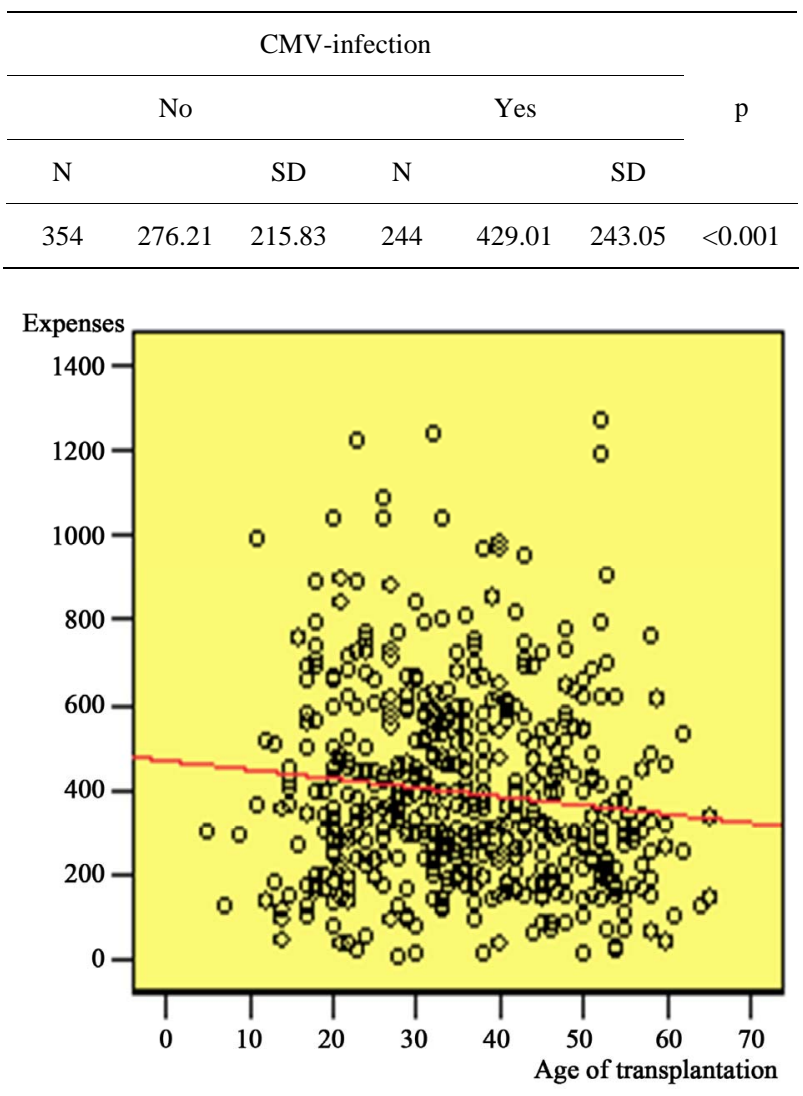

Figure 1. Relation of cost and patients age at the moment of transplantation.

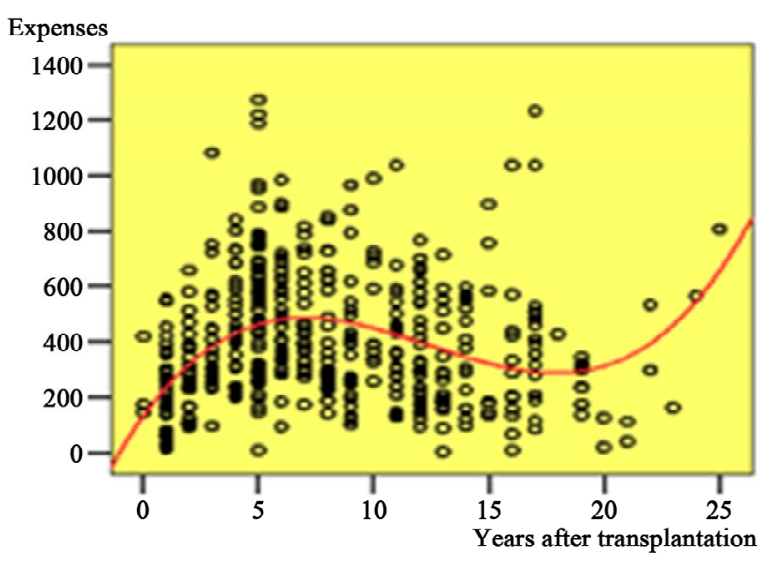

Figure 2. Relation among pharmacotherapy cost and years after transplantation. 
higher cost of pharmacotherapy and the difference is statistically significant.

Due to the important effect on pharmacotherapy cost of CMV-infections other possible factors that could lead to their development were analyzed. The frequency of the CMV infection was found to depend on the country where the transplantation was made. Out of all 19 countries only Pakistani transplanted patients $(n=69)$ developed statistically significant CMV-infections at a greater frequency $(\mathrm{p}<0.01)$.

Patients' age at the moment of transplantation did not influence the CMV-infection frequency but in general patients less than 30 years of age have more CMV infections than other patients $(\mathrm{p}<0.05)$.

\section{Discussion}

To our knowledge this is the first Bulgarian study of prescribing practice and changes in pharmacotherapy cost of kidney transplant patients. In contrast with other countries all kidney transplant patients in Bulgaria receive standard pharmacotherapy that is $100 \%$ reimbursed despite of the fact that they might be transplanted in other country as is the case for lots of patients [12-14]. All of the contemporary immune suppressors were prescribed in the kidney transplant patients. The prescribing is similar with the reported practice in other studies $[10$, 11].

Our study shows that the average monthly cost of pharmacotherapy decreases during 2006-2011. This could be explained partly with the introduction of three generic version of the most often prescribed medicines (azathioprid, mycophenolate mofetil and ciclosporin). It leads to price reduction and thus influences the pharmacotherapy cost.

Three other major drivers of the pharmacotherapy cost are patients' age and CMV-infections, as well as the place of transplantation. Patients age influence the cost negatively that could be explained with the decrease in the average daily dose of the immune suppressors. The dose decrease is a common practice that is used to increase patients' compliance and therapy intensity during the years [15]. On the other hand, the age when the transplantation was done influenced the cost of therapy positively as was shown also from other studies [16-18]. The CMV-infections logically increase the cost due to the addition of one more medicine to the standard immune suppression.

The created regression models provide us with the opportunity to analyze future tendencies in the cost of pharmacotherapy and thus to select group of patients with expected changes in pharmacotherapy cost. We did expect that the patients older than 55 years at the moment of transplantation will have higher pharmacotherapy cost but this was not the case. The only logical explanation could be the dosage decrease performed to protect patients' immunity, as was explained above, but this idea needs further analysis. The second regression model revealed that for the patients living with graft more than 18 years an increase in the pharmacotherapy cost could be expected. This could be used by reimbursing institutions for budget purposes.

\section{Conclusion}

Pharmacotherapy cost of kidney transplant patients in Bulgaria is decreasing as a result of introduction of generic immune suppressors. Important factors influencing pharmacotherapy cost are patients' age at the moment of transplantation, country of transplantation, generic medicines introduction and CMV infections. Those factors influence the statistically significant cost of pharmacotherapy.

\section{REFERENCES}

[1] E. Naumova, P. Panchev, P. J. Simeonov, et al., "Organ Transplantation in Bulgaria,” Cell Tissue Bank, Vol. 9, No. 4, 2008, pp. 337-342. http://dx.doi.org/10.1007/s10561-007-9035-2

[2] M. First, "Immunosupressive Agents and Their Actions," Transplantation Proceedings, Vol. 34, No. 5, 2002, pp. 1369-1371. http://dx.doi.org/10.1016/S0041-1345(02)02893-2

[3] A. H. Miners, G. Yao, J. Raftery and R. S. Taylor, “Economic Evaluations of Calcineurin Inhibitors in Renal Transplantation: A Literature Review,” Pharmacoeconomics, Vol. 25, No. 11, 2007, pp. 935-947. http://dx.doi.org/10.2165/00019053-200725110-00004

[4] R. L. Morton, K. Howard, A. C. Webster, G. Wong and J. C. Craig, "The Cost-Effectiveness of Induction Immunosuppression in Kidney Transplantation,” Nephrology Dialysis Transplantation, Vol. 24, No. 7, 2009, pp. 22582269. http://dx.doi.org/10.1093/ndt/gfp174

[5] S. D. Sullivan, L. P. Garrison Jr. and J. H. Best, "The Cost Effectiveness of Mycophenolate Mofetil in the First Year after Primary Cadaveric Transplant. U.S. Renal Transplant Mycophenolate Mofetil Study Group,” Journal of the American Society of Nephrology, Vol. 8, No. 10, 1997, pp. 1592-1598.

[6] D. Chaib-Eddour, H. Chaib-Eddour, J. Malaise, et al., "Cost of Renal Transplant in Belgium," Transplantation Proceedings, Vol. 37, No. 6, 2005, pp. 2819-2820. http://dx.doi.org/10.1016/j.transproceed.2005.05.035

[7] J. Chetwynd and C. Swainson, "The Cost of Renal Transplants," The New Zealand Medical Journal, Vol. 100, No. 822, 1987, p. 247.

[8] A. G. Diethelm, J. A. Lee, S. L. O’Brien, et al., “Cost Analysis of Renal Transplantation in a Veterans Administration Hospital,” Military Medicine, Vol. 142, 1977, p. 286.

[9] M. A. Gentil, F. González-Roncero, C. Cantarell, et al., 
"Effect of New Immunosuppressive Regimens on Cost of Renal Transplant Maintenance Immunosuppression,” Transplantation Proceedings, Vol. 37, No. 3, 2005, pp. 14411442.

http://dx.doi.org/10.1016/j.transproceed.2005.02.012

[10] E. K. L. Lee and P. L. Tseng, "Retrospective Study on the Utilization and Cost of Immunosuppressive Agents among Kidney Transplant Recipients in Taiwan: A 5-Year Review," Transplantation Proceedings, Vol. 40, No. 7, 2008, pp. 2214-2271. http://dx.doi.org/10.1016/j.transproceed.2008.07.003

[11] E. K. L. Lee, T. M. Cham and P. L. Tseng, "A Retrospective Study on the Utilization of and Expenditure for Immunosuppressants for Organ Transplant Recipients in Taiwan-Updated to 2006," Transplantation Proceedings, Vol. 42, No. 3, 2010, pp. 961-965. http://dx.doi.org/10.1016/j.transproceed.2010.03.013

[12] E. F. Yena, K. Hardinger, D. C. Brennan, et al., "CostEffectiveness of Extending Medicare Coverage of Immunosuppressive Medications to the Life of a Kidney Transplant,” American Journal of Transplantation, Vol. 4, No. 10, 2004, pp. 1703-1708. http://dx.doi.org/10.1111/j.1600-6143.2004.00565.x

[13] National Peoples Assembly, "Law for Organ, Tissues and Cells Transplantation,” Governmental Newspaper, Vol. 83, 2003.
[14] Ministry of Health, "Regulation 34 for the Order of Payment from the Governmental Budget the Therapy of the Bulgarian Citizens That Is Not Covered by the Obligatory Health Insurance,” Governmental Newspaper, Vol. 95, 2005.

[15] S. K. Takemoto, B. W. Pinsky, M. A. Schnitzler, et al., "A Retrospective Analysis of Immunosupression Compliance, Dose Reduction and discontinuation in Kidney Transplant Patient,” American Journal of Transplantation, Vol. 7, No. 12, 2007, pp. 2704-2711. http://dx.doi.org/10.1111/j.1600-6143.2007.01966.x

[16] E. Nemati, A. R. Saadat, M. Hashemi, et al., "Causes of Rehospitalization after Renal Transplantation; Does Age of Recipient Matter?” Transplantation Proceedings, Vol. 39, No. 4, 2007, pp. 970-973. http://dx.doi.org/10.1016/j.transproceed.2007.03.078

[17] T. F. Page and R. S. Woodward, "Cost of Lifetime Immunosuppression Coverage for Kidney Transplant Recipients,” Health Care Financing Review, Vol. 30, 2008, p. 95.

[18] E. Erek, M. S. Sever, E. Akoglu, et al., "Cost of Renal Replacement Therapy in Turkey,” Nephrology, Vol. 9, No. 1, 2004, pp. 33-38. http://dx.doi.org/10.1111/j.1440-1797.2003.00218.x 